\title{
Yet Another Confusion About Time Travel
}

\author{
Giuliano Torrengo \\ University of Milan
}

\begin{abstract}
I argue that, contrary to an idea to be found in popularizations of time travel, one cannot more easily multiply oneself by taking younger versions of oneself back in time than by travelling back in time on one's own. The reason is that the suggested multiplication of the traveller is, from a global perspective, only apparent.
\end{abstract}

\section{Keywords}

Time-travel, duplication, identity, space-time, fallacious reasoning

Most philosophers think that travelling back in time is at least logically possible, because it does not entail changing the past ${ }^{1}$ and because other arguments against self-consistent time travel are not compelling ${ }^{2}$. I am with the majority on this issue. However, travelling into the past can have strange consequences. One is outlined by P. Davies:

Travel into the past takes an air of absurdity when the time traveller meets his younger self, for then there will be two of him. [...] And it needn't stop there. You could invite your (slightly) younger self to accompany you in a similar trip back another day, when there will be three of you. Nothing prevents this process being repeated again and again. By making successive hops back in time, the time traveller could accumulate many copies of himself in one place (Davies 2002: 111).

\footnotetext{
${ }^{1}$ An exception is (Goddu 2003).

${ }^{2}$ See, for instance, the arguments in (Grey 1999), and the reply in (Dowe 2000).
}

Disputatio, Vol. V, No. 35, May 2013

Received: 21/01/2012. Revised: 28/06/2012. Accepted: 05/10/2012 
This suggests that by taking more and more versions of yourself (or of any other object around) back in time with you, you could multiply yourself (or any other object around) effortlessly. Indeed, right after this passage, Davis suggests that in this way you could get very rich very easily using this strategy. Suppose that at 10 o'clock you own a gold bar and you have a time machine. You could then take the gold bar back in time with you to 9.55. Here, you take the (slightly) younger instance of the gold bar along with the older instance of it that is already in your hands on a trip back to 9.50. When you arrive there will be three gold bars...... and so on......by hopping back in time along with more and more gold bars each hop, you can accumulate an enormous quantity of gold.

It is tempting to follow this line of reasoning. However, it is fallacious. In order to see it, focus on 9.55, when an older version of yourself exits from the time machine with a gold bar and takes the gold bar that a younger version of yourself is holding in her hand in order to travel a further five minutes into the past with two gold bars. If the gold bar that she takes from her younger self is the same one that she takes with her back in time at 10 o'clock, then at 9.55 it cannot have been taken by her to a trip back to 9.50 (unless she brought it back). That this is so is because if she had taken it in the past (and not brought it back), the gold bar would have not been there at 10 o'clock! And the same, of course, goes for Davies' original example: at 9.55 your younger self cannot go into the past, if she will enter the time machine at 10 o'clock. Time travel without contradictions entails that the events that a time traveller encounters in her personal time are the very same that everybody else encounters in external time; it is just that they are ordered differently ${ }^{3}$. Thus, if you did not (external time) enter a time machine with your older self, you will not (personal time) do it. (And what if you try anyway? The standard answer is that something would prevent you from doing it: you slip on a banana peel before getting to it, or you change your mind, or ... ).

\footnotetext{
${ }^{3}$ Personal time is that which is measured by a clock attached to the traveller, such as her heart-beats or her wrist-watch; external time is that measured by a clock attached to any object that is at rest with respect to the system of reference
} 
This does not mean that you cannot ever take younger or older versions of yourself back in time. If you did it (external time), then you will do it (personal time). However, taking one or more versions of yourself into the past would not get you many versions of yourself in (roughly) the same place any more easily than coming back many times near the same event without any version of you by your side. Kidnapping or sharing a time machine with a former instance of yourself does not lead to further extravagances in time travelling. To see that, consider a simplified spacetime diagram (fig. 1) that represents the world-line of the time traveller in external time by means of one spatial coordinate and one temporal coordinate along two Cartesian axes ${ }^{4}$. Travelling with a younger version of yourself into the past means simply that in your personal time you have already travelled into the past, and the fact that you have done it with an older version of yourself means simply that your time-line bends over very close to a previous part of itself. Your world-line as a time traveller is one continuous line in the diagram, which cannot bifurcate when you take a younger version of yourself into the past with you.

that the non-travellers share (typically, the Earth). If no time travel takes place, the distinction between personal time and external collapses (apart from tiny relativistic corrections). See Lewis 1976, and MacBeath 1982 for a generalized version.

${ }^{4}$ Such a diagram is simplified, not only because it represents one spatial dimension out of three, but also because it represents spacetime as flat and simply connected, which implies local backwards causation if there is to be time travel into the past, see Earman (1995: chap. 6). If there is no local backward causation, and travelling backwards in time is achieved by means of wormholes or other anomalies in a non-simply connected (curved) spacetime, then representing our ordinary coordinate time would be more difficult. However, nothing substantial hinges on this complication in my argument. 


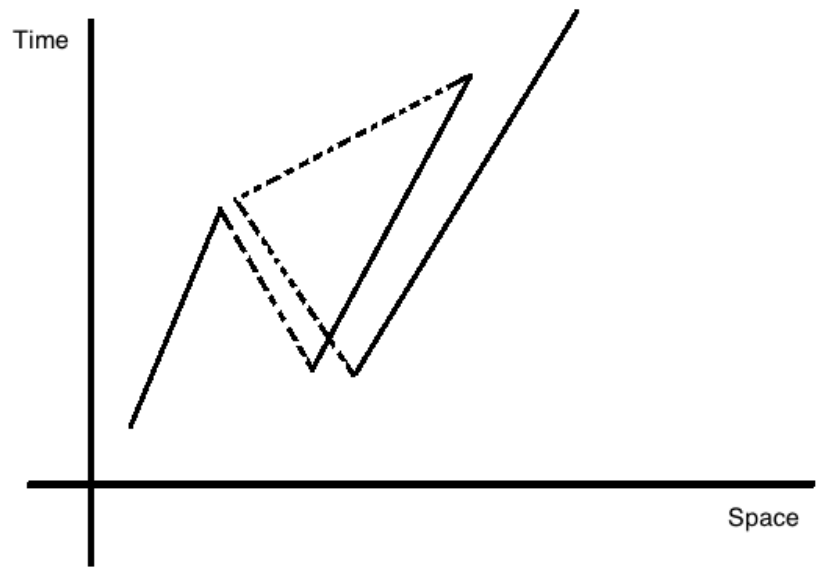

[FIG. 1: World-line of a time travel who 'kidnaps' a younger version of herself into the past. The dotted parts represent backwards movement in public time.]

The only way to get many versions of yourself in (roughly) the same place is to bend your world-line so that segments of it will have exactly the same temporal coordinate and nearly the same spatial coordinate, regardless whether you share a time machine with a younger version of yourself (as in fig. 1) or not (as in fig. 2).

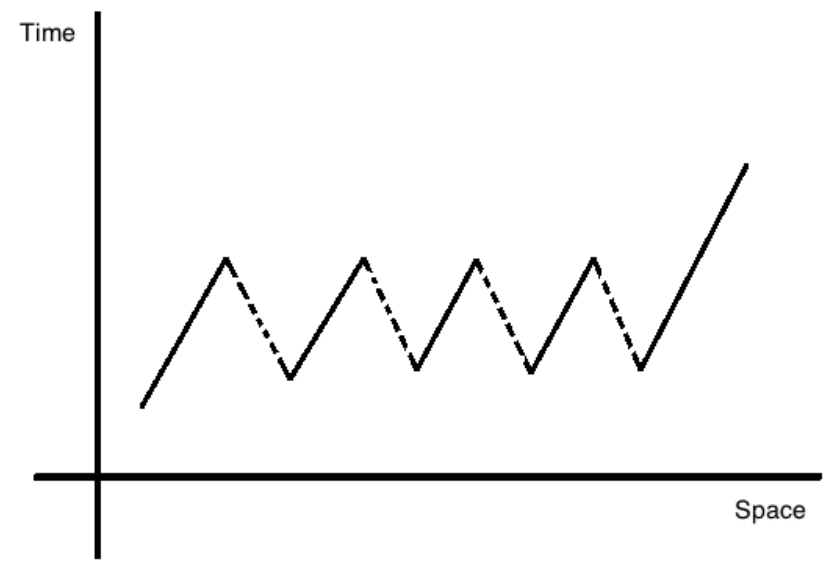

[FIG. 2: World-line of a time travel who goes back several times to (roughly) the same place and meets many versions of herself. Also here the dotted parts represent backwards movement in public time.] 
The situation does not change substantially if time travel is instantaneous, such as if it is achieved by a 'jump drive' or something similar. It is true that in that case, the time traveller's world-line will not be continuous. The world-line of such a time traveller would look as that in fig. 1 or fig. 2 but without the backward traits (i.e. the dotted parts). However, if we connect in the diagram each departure event with its correlate arrival event (according to the personal time of the traveller) by a dotted line, and we call the sum of her normal world-line segments of the time travel and the dotted segments in the diagram her quasi-world-line, we end up with one continuous quasi-world-line, which will not bifurcate in the event that a time traveller from the future takes a younger self with her into the past or future (it will look exactly as those in fig. 1 and fig. 2). The same goes, of course, for any objects a time traveller takes along with her.

Even if the only 'multiplication' of objects and people allowed by self-consistent backwards time travel in one temporal dimension is that implied by the bends of a traveller's world-line, one may argue that that is good enough to multiply things without much effort, and thus to get rich easily. One cannot multiply her investment by making successive hops back in time with more and more versions of a gold bar with her, but one can take a gold bar back and forth in time in order to have many versions of it all gathered at the same time roughly in the same place. This is true, but it does not mean that time travel would give you free copies of your gold bar. What looks like a multiplication from a local perspective is just a bent world-line from a global point of view. The best that time travel can get you is a (zero rate) loan from a future self of yours. To see the point, consider the following story (with the help of Fig. 3). You own a gold bar and a time machine. At time $t$, you put your gold bar on a table in front of the time machine and enter the time machine for a 10-year trip into the future, at time t'. There, you find the gold bar that you left on the table 10 years before, pick it up and take it with you on a trip back to time $t$. Then you put the older version of the bar on the table, and you return - empty handed - to t'. Here, you take a still older version of the bar and you take it with you to t... Do that $\mathrm{n}$ times, stop 
at $\mathrm{t}$, and you will have $\mathrm{n}+1$ gold bars that you can spend however you like. Or can you?

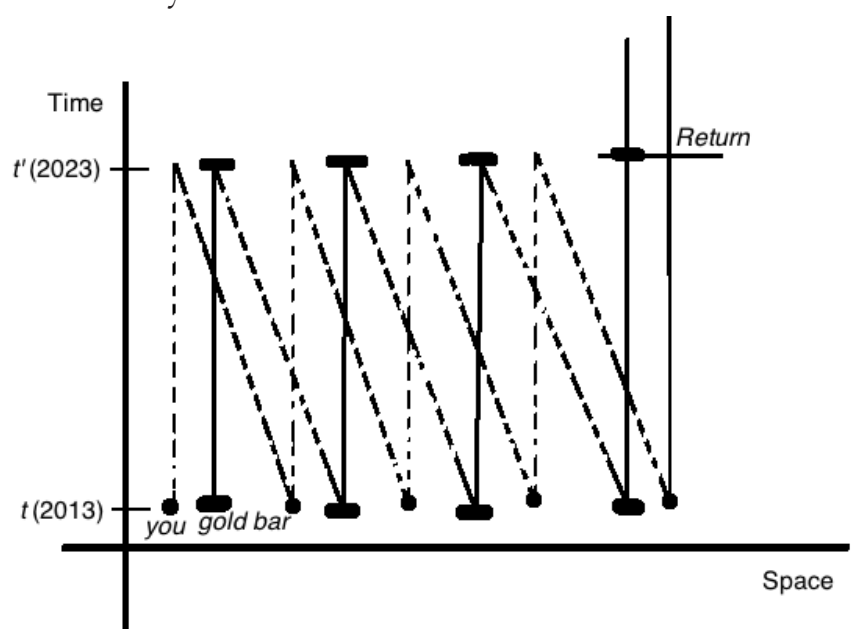

[FIG. 3: World-line of a time traveller (you) who travel back and forth between $t$ and $t$ ' leaving each time on the table at $t$ a version of a gold bar that he has taken from the same table at $t$ '. Dotted segments stand both for backward and forward time travel. $t$ ' is the 'Return' time, when all but one gold bar has to be given back.]

To see whether the story is coherent, and its consequences, think of it as told by someone witnessing the events at $t$ and a $t$ '. In external time, all the arrivals and the departures are simultaneous. At $t, n$ versions of the traveller arrive from the future, leave a gold bar on the table, and $\mathrm{n}-1$ of them embark on a travel to the future with nothing in their hands. The only version of the traveller who stays there (the older one) is indeed left with $\mathrm{n}+1$ gold bars for her to spend however she likes. Yet the story is not over. At $\mathrm{t}^{\prime}, \mathrm{n}-1$ versions of the travellers will arrive from the past to take with them a gold bar each. If the gold bars weren't there at t', at $t$ the traveller could not have received them at $t$. The moral, then, is that the time traveller cannot change the $\mathrm{n}$ gold bars into currency, spend it all, and forget about it. After t' there will be only one gold bar around. The extra richesse she received has to be given back. (What if the time travel tries to not give back the extra bars? Again, she will fail, or else she would have not received them.) The reason is that from a global perspective, no multiplication has taken place. If we look at the interval 
between $t$ and $t^{\prime}$ only, it seems there is more gold than if we had not taken the bar to and fro in time. Yet in spacetime as a whole, we find as much gold as if the bar had not travelled in time at all. And the same goes for persons, of course. If someone's life span is 75 years in personal time, then in spacetime as a whole we find the events composing those 75 years; and that is what we find both in the case in which one is a frantic time traveller and in the case in which one does not travel in time at all.

One may by puzzled by the fact that all departures and arrivals happen at the same time. However, it is easy to see that nothing hinges on this simplification. Draw (as in Fig. 4) the world-line (or quasi-world-line) of a time travelling object $O$. Call B the event of $O$ 's coming into being, and D the event of $O$ 's extinction. Now call $\mathrm{L}$ the lower arrival from the future of $O$ in the diagram, which occurs at a date before which (in external time) $O$ never arrives via backwards time travel, and $U$ the upper arrival from the past, which occurs at a date after which (in external time) $O$ never arrives via forward time travel. It is easy to see that before $\mathrm{L}$, there can exist at most one version of $O$; more precisely, there is one if $\mathrm{B}$ occurs before $\mathrm{L}$, none if it occurs after. Similarly, after $U$ there can exist at most one version of $O$; more precisely, there is only one if $\mathrm{D}$ occurs after $\mathrm{U}$ and none if it occurs before $\mathrm{U}$.

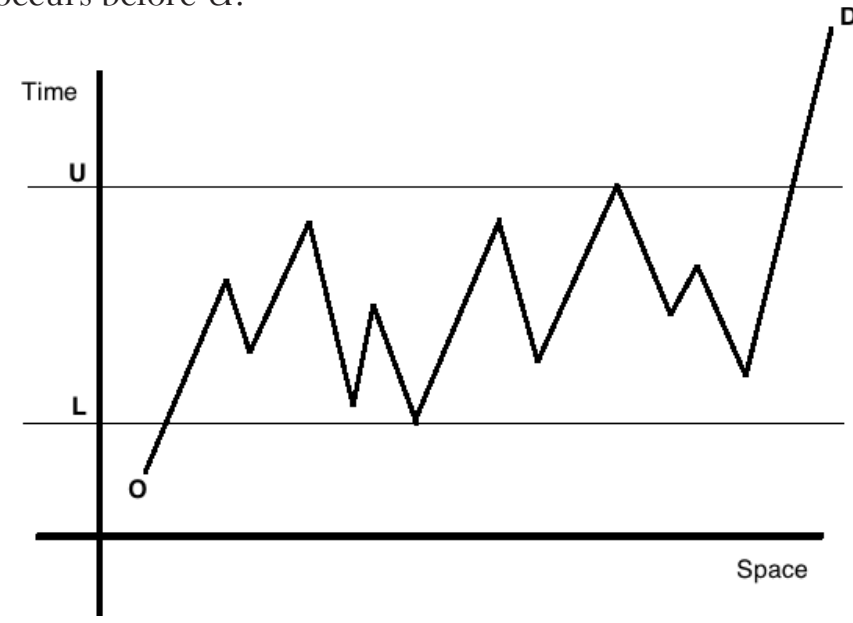

[FIG. 4] 
We now have sufficient information to draw the conclusion. We cannot find instances of the gold bar around after the upper limit $\mathrm{U}$ at which the last (in external time) of our younger selves comes to take what has previously been lent to $\mathrm{us}^{5}$. This situation makes all the richesse we receive from the future a loan, and not a gift, and in general the 'multiplication' of persons and objects obtained by time travelling is, from a global perspective, just an illusion ${ }^{6}$.

\section{Giuliano Torrengo Department of Philosophy, University of Milan Via Festa del Perdono 7, 20122 - Milano, Italy giuliano.torrengo@unimi.it}

\section{References}

Davies, Paul. 2002. How to build a Time Machine. London: Penguin Books.

Dowe, Phil. 2000. The Case for Time Travel. Philosophy 75: 441-51.

Earman, John. 1995. Bangs, Crunches, Whimpers, and Shrieks: Singularities and Acausalities in Relativistic Spacetimes. New York and Oxford: Oxford University Press.

Goddu, Geoffrey C. 2003. Time Travel and Changing the Past (or how to kill yourself and live to tell the tale). Ratio 16: 16-32.

Grey, W. 1999. Troubles with Time Travel. Philosophy 74: 55-70.

Lewis, David K. 1976. The Paradoxes of Time Travel. American Philosophical Quarterly 13: $145-152$.

MacBeath, Murray. 1982. Who Was Dr Who's Father?. Synthese 51: 397-430.

${ }^{5}$ Note that if the upper limit of the time travel of the bar is after our death, we have to take care that when we die, $\mathrm{n}$ bars will stay in the place where our former self has found them before taking them back in time; if we do not manage to do that, we will not have managed to provide the loan to ourselves either.

${ }^{6}$ Thanks to two anonymous referees for useful comments. I acknowledge financial supports from the projects FFI2011-29560-C02-01 and FFI2011- 25626 of the Spanish Ministerio de Ciencia e Innovacion (MICINN). 